\title{
Government Expenditure Financing in the Money-in-the-Production-Function Model
}

\author{
Akihiko Kaneko1, Daisuke Matsuzaki2 ${ }^{*}$ \\ ${ }^{1}$ Faculty of Political Science and Economics, Waseda University, Tokyo, Japan \\ ${ }^{2}$ Faculty of Economics, Toyo University, Tokyo, Japan \\ Email: *matsuzaki@toyo.jp
}

How to cite this paper: Kaneko, A. and Matsuzaki, D. (2018) Government Expenditure Financing in the Money-in-the-Production-Function Model. Theoretical Economics Letters, 8, 119-134. https://doi.org/10.4236/tel.2018.82008

Received: December 5, 2017

Accepted: February 3, 2018

Published: February 6, 2018

Copyright ( 92018 by authors and Scientific Research Publishing Inc. This work is licensed under the Creative Commons Attribution International License (CC BY 4.0).

http://creativecommons.org/licenses/by/4.0/

(c) (i) Open Access

\begin{abstract}
In this study, we consider a scenario in which the government resorts to an income and inflation tax to finance its expenditures in the money-in-theproduction-function model. We show that a financing shift from the inflation tax to the income tax increases the real money holdings-to-capital ratio because the accumulation of capital is less favorable than holding money. We also find that a country's economic growth rate is maximized if all government expenditures are financed through an income tax. For welfare maximization, the government should set the income tax rate higher than the growth maximizing tax rate and reimburse the excess revenue using money contraction.
\end{abstract}

\section{Keywords}

Money-in-Production Function, Financing Methods, Endogenous Growth Model

\section{Introduction}

Since the pioneering work on the endogenous growth theory by scholars, such as Romer [1] and Lucas [2], the effect of taxation on economic growth has been one of the most carefully examined topics in the field of economics (for example, Rebelo [3] and Jones et al. [4]). Recently, the related topic of the effect of different government expenditure financing on economic growth and welfare has been examined extensively in the literature, including Grinols and Turnovsky [5], Turnovsky [6], Palivos and Yip [7], Pecorino [8], and Gokan [9]. These papers have considered the mix of tax, bond, and money financing to meet different government expenditures. Our paper considers the effect of government policy that involves resorting to income tax and money financing. Our study al- 
so considers the effect of government policy that involves resorting to an income tax and an increase in the nominal money growth rate (inflation tax).

Another distinctive feature of our paper is that we use the money-in-theproduction-function (MIP) model. Grinols and Turnovsky [5], Turnovsky [6], Palivos and Yip [7], and Gokan [9] adopted the money-in-the-utility-function (MIU) model, whereas Palivos and Yip [7] used the cash-in-advance (CIA) model, and Pecorino [8] developed his model based on the transaction cost model. To the best of our knowledge, no study has yet dealt with government financing through income tax and inflation tax in the MIP model.

A number of studies undertake a theoretical or empirical examination of the MIP model. Originally developed by Levhari and Patinkin [10] and Fischer [11], the MIP model assumes that economic agents, especially firms, must divert part of the employed factors of production to expensive activities. Even in recent studies, such as Benhabib et al. [12], Meng and Yip [13], Suen and Yip [14], Shaw et al. [15], and Lai and Chin [16] the implications of monetary policy or the dynamic property of a balanced growth path (BGP) equilibrium in a situation in which money is introduced as a factor of production are examined. ${ }^{1}$

The main findings of our model are as follows. First, we find that a financing shift from the inflation tax to the income tax increases the real money holdings-to-capital ratio because the policy change leads to a situation in which the accumulation of capital is less preferable than holding money. Second, if the government's purpose is to maximize the growth rate, it should make the level of money supply constant, that is, zero inflation tax and finance all expenditures by imposing an income tax. Furthermore, for welfare maximization, the government should set the income tax rate higher than the growth maximizing tax rate and reimburse the excess revenue using money contraction.

This result on welfare is inconsistent with the finding of Palivos and Yip [7] but consistent with the finding of Pecorino [8]. Palivos and Yip [7] showed that the inflation tax is always more favorable than the income tax on economic growth and welfare under the CIA constraint, whereas Pecorino [8] demonstrated that an interior optimal mixture of the inflation tax and income tax must exist under a transaction cost technology. Pecorino [8] concluded that this difference between the results comes from the responsiveness of the tax base, that is, real money balances. In the CIA model, the velocity of money is always constant but may vary under a transaction cost technology. In the MIP model, the velocity also undergoes a change because firms change the ratio of input in response to a policy change. Our result suggests that the optimal composition of government financing depends on how to incorporate money into the model.

The remainder of this paper is organized as follows. Section 2 develops a MIP endogenous growth model. Section 3 compares the effect of the income tax and inflation tax on the growth rate. In Section 4, we discuss the effect of this policy

${ }^{1}$ For the empirical evidence in support of the finding that money is an important factor in the production function, see Sinai and Stokes [17], Simos [18], Hasan and Mahmud [19], and Saygili [20]. 
change on welfare. Section 5 summarizes our findings. Finally, the limitation of research and further research are made in Section 6.

\section{Model}

We consider a closed economy that consists of firms, households, and the government. Furthermore, we assume that only one final good can be used for both consumption and investment.

\subsection{Firms}

Before undertaking our analysis, we first normalize the number of households and firms as being equal to 1 . Following Suen and Yip [14], we specify a MIP model with $A k$ technology as follows: ${ }^{2}$

$$
y(t)=[1-\phi(m(t) / A k(t))] A k(t),
$$

where $y(t)$ is the net output and $k(t)$ and $m(t)$ are, respectively, physical capital and real money employed in a firm at time $t$. In addition to acquiring the factors of production, firms incur transaction costs in the commodity market in connection with bargaining, setting prices, and wholesale purchasing and selling of goods among firms. These costs increase with the growth in production by the firm, but are lessened when the firm has access to money. We use the function $\phi$ to represent the pecuniary transaction cost. Increased production by the firm is usually accompanied by an increase in the volume of transactions, which occasions an increased loss in real output. Therefore, the partial derivative of the function $\phi$ with respect to $A k$ is assumed to be positive. Greater firm access to money facilitates smoother transactions. Thus, the partial derivative of the function $\phi$ with respect to $m$ is assumed to be negative. We also assume that the transaction cost function $\phi$ has constant returns to scale in $A k$ and $m$. Normalizing $A$ to 1 and defining $\omega(t)$ as $k(t) / m(t)$, we reduce the net production function to:

$$
y(t)=f(\omega(t)) k(t),
$$

where $f^{\prime}(\omega(t))>0, f^{\prime \prime}(\omega(t))<0$.

A firm's profit is defined as its after-tax revenue minus the cost of leasing capital assets and borrowing money from households, which is represented by:

$$
\left(1-\tau_{y}\right) y(t)-r(t) k(t)-R(t) m(t),
$$

where $r(t)$ is the rental rate of physical capital, $R(t)$ is the rental rate of money or the cost of borrowing money from households, and $\tau_{y} \in[0,1]$ is the income tax. Considering that the representative firm maximizes profits, the first-order conditions for profit maximization are as follows:

$$
\left(1-\tau_{y}\right)\left[f(\omega(t))-f^{\prime}(\omega(t)) \omega(t)\right]=r(t),
$$

${ }^{2}$ Suen and Yip [14] used this specification to analyze the property of the balanced growth equilibrium and the relationship with the monetary expansion growth rate. Chen et al. [21] used this general form to analyze the relationship between the interest rate rule and both inflation and economic growth in an open economy. 


$$
\left(1-\tau_{y}\right) f^{\prime}(\omega(t))=R(t) .
$$

The firm compares the after-tax marginal product of each input to its rental rate, $r(t)$ or $R(t)$.

\subsection{Households}

A representative household gains utility from its consumption. This representative household can earn revenue in two ways: from its savings or by lending money to firms. The household's nominal budget constraint is as follows:

$$
p(t) \dot{k}(t)+\dot{M}(t)=p(t) r(t) k(t)+p(t) R(t) m(t)-p(t) c(t),
$$

where $M(t)$ is nominal money, $p(t)$ is the commodity price, and $c(t)$ is the household's real consumption. A dot $\left({ }^{\circ}\right)$ means a time derivative. Dividing both sides by $\pi(t)$, we obtain the household's real budget constraint as follows:

$$
\dot{a}(t)=r(t) a(t)+(R(t)-\pi(t)-r(t)) m(t)-c(t),
$$

where $\pi(t)$ is the inflation rate of the commodity price $p(t)$ and $a(t)$ is the total real asset, that is, the sum of $k(t)$ and $M(t) / p(t)(\equiv m(t))$. The lifetime utility of the household is as follows:

$$
\int_{0}^{\infty} \frac{c(t)^{1-\sigma}-1}{1-\sigma} \mathrm{e}^{-\rho t} \mathrm{~d} t,
$$

where $\rho$ is the rate of the time preference and $1 / \sigma$ is the elasticity of substitution for the utility function. Throughout this paper, $\sigma$ is assumed to be greater than $1 .^{3}$

The household maximizes its lifetime utility (5) subject to its budget constraint (4). The Hamiltonian function associated with this problem is

$$
J(t)=\frac{c(t)^{1-\sigma}-1}{1-\sigma}+\lambda(t)(r(t) a(t)+(R(t)-\pi(t)-r(t)) m(t)-c(t)),
$$

where $\lambda(t)$ is the costate variable. Thus, the necessary conditions for optimality are:

$$
\begin{gathered}
\frac{\partial J(t)}{\partial c(t)}=0 ; c(t)^{-\sigma}-\lambda(t)=0, \\
\dot{\lambda}(t)=\rho \lambda(t)-\frac{\partial J(t)}{\partial a(t)} ; \dot{\lambda}(t)=-(\rho-r) \lambda(t), \\
\frac{\partial J(t)}{\partial m(t)}=0 ; \lambda(t)(R(t)-\pi(t)-r(t))=0 .
\end{gathered}
$$

From these necessary conditions, we develop the following Euler equation and no-arbitrage condition:

$$
\begin{aligned}
\dot{c}(t) / c(t) & =(r(t)-\rho) / \sigma, \\
r(t) & =R(t)-\pi(t) .
\end{aligned}
$$

Although the firms pay $R(t)$ to the household for borrowing one unit of real ${ }^{3}$ Ogaki and Reinhart [22] reported that $\sigma$ was larger than 1 in the United States. 
money, the value of real money decreases at the rate of inflation. Therefore, the return on real money to the household is $R(t)-\pi(t)$. This equation indicates that the return on $k(t)$ must equal that on $m(t)$ in a state of the equilibrium in which both physical capital and real money are held by the household. The transversality condition must also be satisfied as the following necessary condition:

$$
\lim _{t \rightarrow \infty} \lambda(t) a(t) \mathrm{e}^{-\rho t}=0
$$

In Appendix A, we illustrate that the transversality condition is satisfied at the BGP when $\sigma$ is greater than 1 .

\subsection{Government}

The government imposes an income tax and issues new money for non-negative nominal wasteful government consumption of $p(t) G(t)$. The government's nominal budget constraint then becomes:

$$
p(t) G(t)=\tau_{y} p(t) y(t)+\mu M(t),
$$

where $\mu$ is the growth rate of nominal money. In real terms:

$$
G(t)=\tau_{y} y(t)+\mu m(t) .
$$

\subsection{Dynamics}

For ease of exposition, we suppress the time index and the dependence of $\omega$ with what follows. As the economy experiences long-run growth, we assume that the share of government expenditures to output is constant, $g$, such that $g=G / y$. Using the production function in (1), the government budget condition (12) becomes:

$$
\mu=\left(g-\tau_{y}\right) f(\omega) / \omega .
$$

Given a constant monetary growth rate $\mu$, the money market equilibrium requires that $\dot{m} / m=\mu-\pi$. Using Equations (2), (3), and (10) to eliminate $\pi$, we have:

$$
\dot{m} / m=\mu+\left(1-\tau_{y}\right)\left(f(\omega)-f^{\prime}(\omega) \omega-f^{\prime}(\omega)\right) .
$$

Introducing Equations (2), (3), (12), (14), and the total asset constraint into (4), the market equilibrium condition for a commodity is indicated by:

$$
\dot{k} / k=y / k-(G / y)(y / k)-c / k=(1-g) f(\omega)-c / k .
$$

From Equations (2) and (9), the growth rate of consumption can be rewritten as follows:

$$
\dot{c} / c=\left[\left(1-\tau_{y}\right)\left(f(\omega)-f^{\prime}(\omega) \omega\right)-\rho\right] / \sigma .
$$

Defining $c / k$ and $m / k$ as $\chi$ (the consumption-to-capital ratio) and $\omega$ (the real money holdings-to-capital ratio), we have the following autonomous dynamic system from Equations (13), (14), (15), and (16): 


$$
\begin{gathered}
\dot{\chi}=\chi\left\{\frac{1}{\sigma}\left[\left(1-\tau_{y}\right)\left(f(\omega)-f^{\prime}(\omega) \omega\right)-\rho\right]-(1-g) f(\omega)+\chi\right\}, \\
\dot{\omega}=\omega\left[\frac{\left(g-\tau_{y}\right) f(\omega)}{\omega}+\left(1-\tau_{y}\right)\left(f(\omega)-f^{\prime}(\omega) \omega-f^{\prime}(\omega)\right)-(1-g) f(\omega)+\chi\right] .
\end{gathered}
$$

Under the BGP equilibrium, the growth rate of consumption, capital, and real money balances is the same. In Appendix B, we illustrate that the BGP equilibrium is unique and determinate.

\section{Income Tax and Money Financing}

We then compare the effect of income tax and monetary financing on the BGP growth rate of the economy. At a BGP, $\dot{\chi} / \chi=\dot{\omega} / \omega=0$. Introducing $\dot{\chi} / \chi=\dot{\omega} / \omega=0$ into Equations (17) and (18) results in:

$$
\begin{aligned}
& \frac{\left(1-\tau_{y}\right)\left(f(\omega)-f^{\prime}(\omega) \omega\right)-\rho}{\sigma} \\
& =\left(g-\tau_{y}\right) \frac{f(\omega)}{\omega}+\left(1-\tau_{y}\right)\left(f(\omega)-f^{\prime}(\omega) \omega-f^{\prime}(\omega)\right),
\end{aligned}
$$

which gives a BGP equilibrium level of $\omega$. Under a given share of government expenditures, totally differentiating (19) results in:

$$
\frac{\mathrm{d} \omega^{*}}{\mathrm{~d} \tau_{y}}=\frac{\left(1-\frac{1}{\sigma}\right)\left(f\left(\omega^{*}\right)-f^{\prime}\left(\omega^{*}\right) \omega^{*}\right)+\frac{f\left(\omega^{*}\right)-f^{\prime}\left(\omega^{*}\right) \omega^{*}}{\omega^{*}}}{\left(g-\tau_{y}\right)\left(\frac{f^{\prime}\left(\omega^{*}\right) \omega^{*}-f\left(\omega^{*}\right)}{\omega^{* 2}}\right)-\left(1-\tau_{y}\right) f^{\prime \prime}\left(\omega^{*}\right) \omega^{*}\left(1+\frac{1}{\omega^{*}}-\frac{1}{\sigma}\right)} .
$$

An asterisk over a variable represents a BGP. Because $\sigma$ is greater than 1 , the numerator in the right-hand side of (20) is clearly positive. The uniqueness condition of the BGP, (B-2), in Appendix B ensures that the denominator in the right-hand side of (20) is positive. Thus, an increase in the income tax results in an immediate corresponding increase in the value of $\omega^{*}$.

\section{Lemma:}

For a given level of government expenditures, a shift from money financing to income tax financing increases the real money holdings-to-capital ratio.

The intuition behind this result is simple: the government reduces money financing if it raises the income tax for a given share of government expenditures. Thus, with the accumulation of capital being less favorable than holding money, the real money holdings-to-capital ratio, $\omega^{*}$, increases.

We next turn to exploring the growth maximizing tax structure and get next proposition.

Proposition 1:

When income tax financing and money financing are available in an MIP 
model, the government should finance all government expenditures through the income tax to maximize the growth rate of the economy.

Proof: On the BGP equilibrium, the level of capital, money holdings, and consumption grows at the same constant rate. The growth rate of consumption can represent the BGP growth rate, $\theta$. From (9) and (20), we have:

$$
\frac{\mathrm{d} \theta^{*}}{\mathrm{~d} \tau_{y}}=\frac{\left(g-\tau_{y}\right)\left(f\left(\omega^{*}\right)-f^{\prime}\left(\omega^{*}\right) \omega^{*}\right)^{2} / \omega^{* 2} \sigma}{\left(g-\tau_{y}\right)\left(\frac{f^{\prime}\left(\omega^{*}\right) \omega^{*}-f\left(\omega^{*}\right)}{\omega^{* 2}}\right)-\left(1-\tau_{y}\right) f^{\prime \prime}\left(\omega^{*}\right) \omega^{*}\left(1+\frac{1}{\omega^{*}}-\frac{1}{\sigma}\right)} .
$$

From (13), the sign of $g-\tau_{y}$ depends on the sign of $\mu$ and means that the growth maximization condition is $\mu=0$. Thus, if the government's purpose is to maximize the growth rate, it should make the level of money supply constant and all expenditures are financed by imposing an income tax.

Palivos and Yip [7] found that for any given government size, the growth rate in a CIA model is higher under money financing than income tax financing. One important difference between the CIA model and the MIP model is that when only consumption goods purchases are subject to liquidity constraints, the monetary policy is superneutral to economic growth in the CIA model. With each increase in the fraction of investment purchases subject to the CIA constraint, monetary policy has the effect of suppressing growth. However, the distortionary effect of monetary policy does not outweigh that of income tax financing. Alternatively, monetary policy is essentially non-neutral in the MIP model because a higher inflation rate induced by the high rate of monetary expansion increases the opportunity cost of holding money, which depresses real activity. The difference in the model specification results in the opposite outcome: money financing is preferable in the CIA model, whereas income tax financing is preferable in our model. Our result suggests that an optimal composition of government financing depends on the model specification.

\section{Welfare Analysis}

In this section, we investigate the effect of income tax and money financing on welfare. We will see that the optimal income tax rate for welfare is higher than the growth maximizing tax rate. As previously found, all government expenditures are financed by income tax at the maximized growth rate. Thus, the subsequent result indicates that it is optimal for the government to collect more income taxes than a given government expenditure and redistribute the excess revenue through money contraction.

Let us assume that a policy change takes place at time zero. Because the economy is always on the BGP, Equation (9) can be used to determine the level of consumption at time $t(>0)$. More formally, it is represented by:

$$
c(t)=c(0) \mathrm{e}^{\theta^{*} t},
$$

where $c(0)$ is the level of consumption at time zero and $\theta^{*}$ is the growth rate 
at a BGP. Substituting Equation (21) into Equation (5) yields a lifetime utility of:

$$
U=-\frac{c(0)^{1-\sigma}}{(1-\sigma)\left((1-\sigma) \theta^{*}-\rho\right)}-\frac{1}{(1-\sigma) \rho} .
$$

Because there are no transitional dynamics in this model, the lifetime utility is governed by the level of initial consumption and the BGP growth rate.

From Equation (17) and (19):

$$
c(0)=\left[\sigma(1-g) f\left(\omega^{*}\right)-\left(1-\tau_{y}\right)\left(f\left(\omega^{*}\right)-f^{\prime}\left(\omega^{*}\right) \omega^{*}\right)+\rho\right] k(0) / \sigma,
$$

where $k(0)$ is the level of physical capital at time zero. By substituting this equation into Equation (22), the level of welfare at the BGP can be rewritten as follows:

$$
\begin{aligned}
U= & -\frac{\left[\sigma(1-g) f\left(\omega^{*}\right)-\left(1-\tau_{y}\right)\left(f\left(\omega^{*}\right)-f^{\prime}\left(\omega^{*}\right) \omega^{*}\right)+\rho\right]^{1-\sigma} \sigma^{\sigma-1} k(0)^{1-\sigma}}{(1-\sigma)\left((1-\sigma) \theta^{*}-\rho\right)} \\
& -\frac{1}{(1-\sigma) \rho} .
\end{aligned}
$$

From (23), we can derive the next proposition.

Proposition 2:

A welfare maximizing mix of financing collects more income tax revenue than a given government expenditure and reimburses the excess revenue through monetary contraction.

Proof: From the firm's profit maximizing condition $r=\left(1-\tau_{y}\right)\left(f(\omega)-f^{\prime}(\omega) \omega\right),(23)$ can be rewritten as:

$$
U=-\frac{\left\{\sigma(1-g) f\left(\omega^{*}\right)-r^{*}+\rho\right\}^{1-\sigma} \sigma^{\sigma-1} k(0)^{1-\sigma}}{(1-\sigma)\left((1-\sigma) \theta^{*}-\rho\right)}-\frac{1}{(1-\sigma) \rho} .
$$

Differentiating this equation with respect to $\tau_{y}$ gives us:

$$
\frac{\mathrm{d} U}{\mathrm{~d} \tau_{y}}=\frac{-1}{1-\sigma}\left(\frac{\Omega}{\left((1-\sigma) \theta^{*}-\rho\right)^{2}}\right) \sigma^{\sigma-1} k(0)^{1-\sigma},
$$

where

$$
\begin{aligned}
\Omega= & (1-\sigma)\left((1-\sigma) \theta^{*}-\rho\right)\left\{\sigma(1-g) f\left(\omega^{*}\right)-r^{*}+\rho\right\}^{-\sigma} \\
& \times \sigma\left[(1-g) f^{\prime}\left(\omega^{*}\right) \frac{\mathrm{d} \omega^{*}}{\mathrm{~d} \tau_{y}}-\frac{\mathrm{d} r^{*}}{\mathrm{~d} \tau_{y}}\right] \\
& +\left\{\sigma(1-g) f\left(\omega^{*}\right)-r^{*}+\rho\right\}^{1-\sigma}(\sigma-1) \frac{\mathrm{d} \theta^{*}}{\mathrm{~d} \tau_{y}} .
\end{aligned}
$$

Because a BGP growth rate can be represented by the growth rate of consumption, it remains that $\theta^{*}=\sigma^{-1}(r-\rho)$ (see (16)). This implies that $\mathrm{d} r^{*} / \mathrm{d} \tau_{y}=\sigma \mathrm{d} \theta^{*} / \mathrm{d} \tau_{y}$. Therefore, we can rewrite $\Omega$ as follows: 


$$
\begin{aligned}
\Omega= & (1-\sigma)\left((1-\sigma) \theta^{*}-\rho\right)\left\{\sigma(1-g) f\left(\omega^{*}\right)-r^{*}+\rho\right\}^{-\sigma} \sigma(1-g) f^{\prime}\left(\omega^{*}\right) \frac{\mathrm{d} \omega^{*}}{\mathrm{~d} \tau_{y}} \\
& +\sigma\left((1-g) f\left(\omega^{*}\right)-r^{*}\right)\left\{\sigma(1-g) f\left(\omega^{*}\right)-r^{*}+\rho\right\}^{-\sigma}(\sigma-1) \frac{\mathrm{d} \theta^{*}}{\mathrm{~d} \tau_{y}} .
\end{aligned}
$$

$(1-g) f(\omega)$ is the available net production level of government expenditure per capital, where $r$ does not exceed it. Thus, the coefficients of $\mathrm{d} \omega^{*} / \mathrm{d} \tau_{y}$ and $\mathrm{d} \theta^{*} / \mathrm{d} \tau_{y}$ in (24) are positive. From the lemma, $\mathrm{d} \omega^{*} / \mathrm{d} \tau_{y}$ itself is positive. As a result, at the maximum, $\mathrm{d} \theta^{*} / \mathrm{d} \tau_{y}$ should be negative.

This suggests that the optimal income tax rate is higher than the growth maximizing tax rate. At the growth maximizing tax rate $\left(\mathrm{d} \theta^{*} / \mathrm{d} \tau_{y}=0\right)$, all government expenditures are financed only by income tax. In other words, the welfare maximizing mix of government financing is one that collects more income tax revenue than a given government expenditure and reimburses the excess revenue through monetary contraction. ${ }^{4}$

The intuition behind this result is as follows. Despite growth maximization, firms still incur pecuniary transaction costs, which reduce their net production. Thus, firm profits are better off reducing the cost of hiring money, that is, $R$, by contracting the money supply. Assuming that the government can balance its budget, contracting the money supply requires increasing the income tax rate. The proposition implies that the welfare loss incurred through an increase in income taxes is exceeded by the welfare gain through money contraction in our model.

Palivos and Yip [7] showed that money financing is always more favorable than the income tax on welfare under the CIA constraint, whereas Pecorino [8] demonstrated that an optimal mix of the inflation tax and income tax must exist under a transaction cost technology. Pecorino [8] concluded that this difference between the results comes from the responsiveness of the tax base (i.e., real money balances). In the CIA model, the velocity of money is always constant but may vary under a transaction cost technology. In the MIP model, the velocity-defined as $y / m$ in our model-changes because firms change the ratio of input in response to the policy change. Our result confirms that the inflation tax is not a better source than the income tax for expenditure financing when the velocity varies. ${ }^{5}$

We next undertake a numerical simulation. For this analysis, we specify the production function in (1) as the following Cobb-Douglas form:

$$
y=\Lambda \omega^{1-\alpha} k, 0<\alpha<1 .
$$

\footnotetext{
${ }^{4}$ Totally differentiating the government budget condition (13), we have $\mathrm{d} \mu=\left[-\frac{f\left(\omega^{*}\right)}{\omega^{*}}+\left(g-\tau_{y}\right) \frac{f^{\prime}\left(\omega^{*}\right) \omega^{*}-f\left(\omega^{*}\right)}{\omega^{* 2}} \frac{\mathrm{d} \omega^{*}}{\mathrm{~d} \tau_{y}}\right] \mathrm{d} \tau_{y}$. From Lemma and Proposition 1, we conclude that $\mathrm{d} \mu / \mathrm{d} \tau_{y}<0$ at the growth maximizing tax rate.

${ }^{5}$ In our model, the velocity of money is defined as $y / m$. Totally differentiating it gives $\frac{\mathrm{d}(y / m)}{\mathrm{d} \tau_{y}}=\frac{\mathrm{d} f\left(\omega^{*}\right) / \omega^{*}}{\mathrm{~d} \tau_{y}}=\frac{\mathrm{d} \omega^{*}}{\mathrm{~d} \tau_{y}}\left(\frac{f^{\prime}\left(\omega^{*}\right) \omega^{*}-f\left(\omega^{*}\right)}{\omega^{* 2}}\right)<0 . \quad$ The sign is determined by Lemma.
} 
We set the parameters as follows: $\sigma=1.1, \Lambda=0.2, \quad \alpha=0.8, \rho=0.03$, $g=0.15$, and $k(0)=1 .^{6}$

The result is depicted in Figures 1-3. Figure 1 shows the effect of a change in the income tax on a change in the growth rate, whereas Figure 2 and Figure 3 exhibit the effect of a change in the income tax on the growth rate and the utility level. As stated in Proposition 1, the growth rate is maximized at the level at which all government expenditures are paid only by taxes (in this example, $\left.\tau_{y}=0.15\right)$. For welfare maximization, the tax rate should be approximately 0.297 . The monetary growth rate $\mu$ is calculated by (13) as -0.020 .

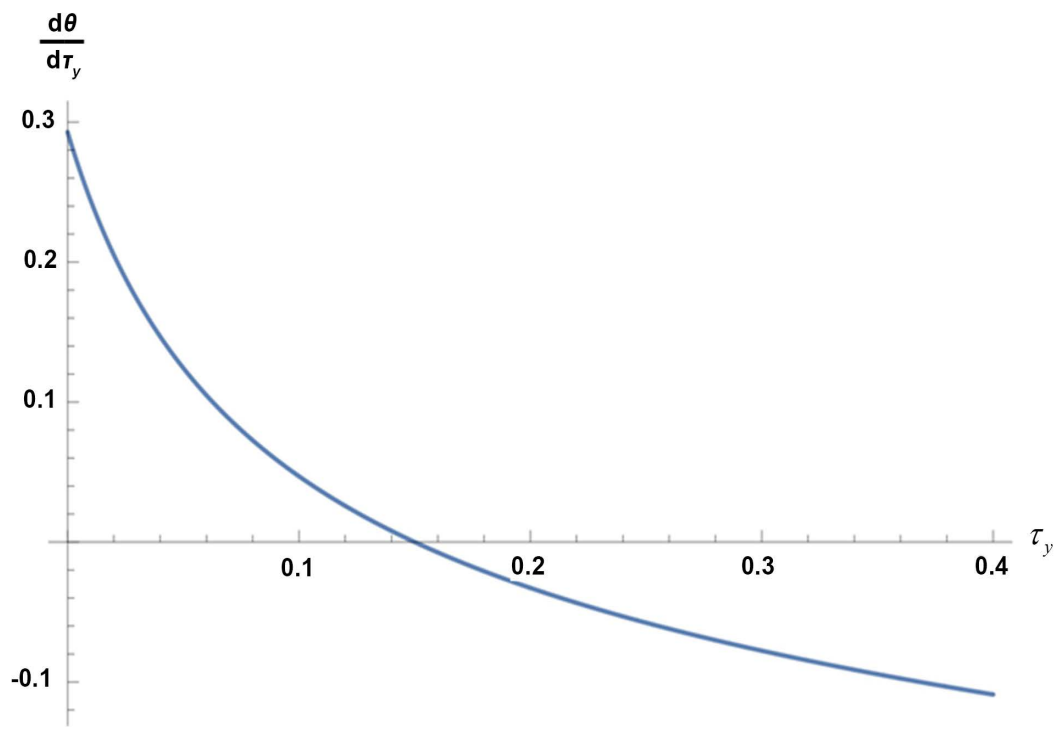

Figure 1. Effect of a change in the income tax on the change in growth rate.

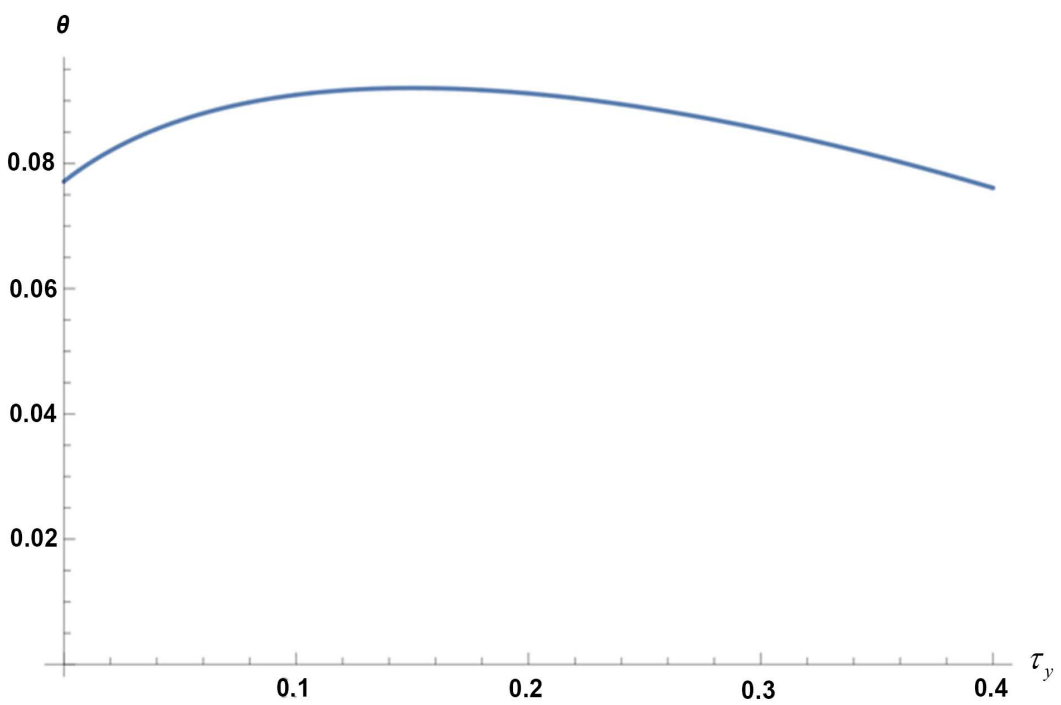

Figure 2. Effect of a change in the income tax on the growth rate.

${ }^{6}$ It is not our purpose to replicate the real economy. We set these parameters to show that at the low (high) level of income taxes, increasing income taxes raises (lowers) the economic growth. Needless to say, these parameters satisfy sufficient conditions for uniqueness and stability of the equilibrium. 


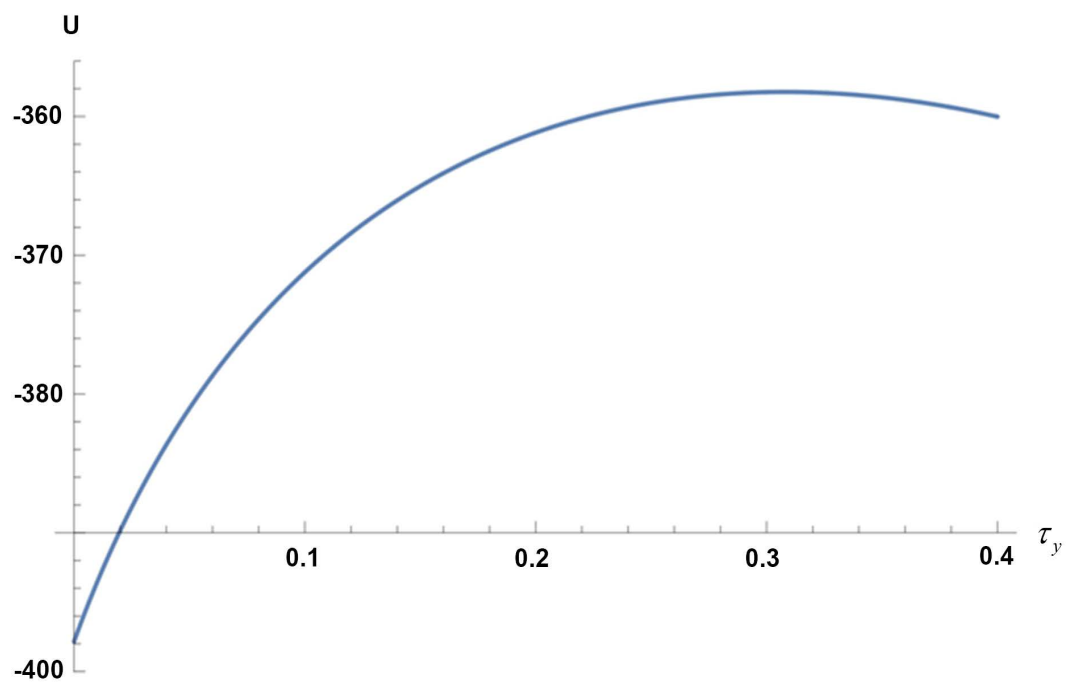

Figure 3. Effect of a change in the income tax on the utility level.

\section{Results}

In this study, we examined the effects of different financing models in the MIP model. First, we find that the financing shift from the inflation tax to income tax increases the real money holdings-to-capital ratio for a given share of government expenditure. Second, we showed that income tax financing is favorable to economic growth, a result that contrasts with the findings of Palivos and Yip [7], who adopted the CIA model. Furthermore, we derived a welfare maximizing policy and found that such a policy is one that collects more income tax revenue than a given government expenditure and reimbursement. In other words, the welfare maximizing tax rate is higher than the growth maximizing tax rate.

\section{Conclusions}

Many monetary models are available, including the MIU and CIA, but they differ in some of their policy implications. Our results suggest that the relative impact of alternative tax changes should be evaluated using the more integrated monetary model.

We used an AK-type production function as the engine of growth, which helps us evaluate the effect of government policy in our model. However, it is a restrictive model. It is worth re-investigating our argument under a more general form of production function.

Several extensions of our study may be useful for future research. First, we used income tax financing to help evaluate the effects of different financing approaches. When examining the substitution between money and physical capital, a focus on capital tax may yield clearer results. Second, we can extend the model to a multi-sector model, according to which we can consider different levels of real money balances in different sectors with a different tax rate for each sector, as well as whether the overall tax burden would be important for growth and welfare. Such a model will also permit us to investigate not only the conse- 
quences of switching financing regimes, but also the consequences of changing the tax burdens on each sector.

\section{Acknowledgements}

This work in part by a Waseda University Grant for Special Research Projects [No. 2017K-012] (Akihiko Kaneko); JSPS KAKENHI Grant Numbers No. 15K03449 and No. 17K03727 (Akihiko Kaneko), and No. 16K03664 (Daisuke Matsuzaki). An early version of this paper was presented in Asian Meetings of the Econometric Society in Delhi, PET 13 in Lisbon, the Kansai Macroeconomics Workshop and the seminar at Waseda University. We would like to thank seminar participants for useful comments and helpful suggestions. The authors are solely responsible for any errors.

\section{References}

[1] Romer, P.M. (1986) Increasing Returns and Long-Run Growth. Journal of Political Economy, 94, 1002-1037. https://doi.org/10.1086/261420

[2] Lucas, R.E. (1988) On the Mechanics of Economic Development. Journal of Monetary Economics, 22, 3-42. https://doi.org/10.1016/0304-3932(88)90168-7

[3] Rebelo, S. (1991) Long-Run Policy Analysis and Long-Run Growth. Journal of Political Economy, 99, 500-521. https://doi.org/10.1086/261764

[4] Jones, L.E., Manuelli, R.E. and Rossi, P.E. (1997) On the Optimal Taxation of Capital Income. Journal of Economic Theory, 73, 93-117.

https://doi.org/10.1006/jeth.1996.2238

[5] Grinols, E. and Turnovsky, S.J. (1993) Risk, the Financial Market, and Macroeconomic Equilibrium. Journal of Economic Dynamics and Control, 17, 1-36. https://doi.org/10.1016/S0165-1889(06)80002-3

[6] Turnovsky, S.J. (1993) Macroeconomic Policies, Growth, and Welfare in a Stochastic Economy. International Economic Review, 34, 953-981. https://doi.org/10.2307/2526974

[7] Palivos, T. and Yip, C. (1995) Government Expenditure Financing in an Endogenous Growth Model: A Comparison. Journal of Money, Credit, and Banking, 27, 1159-1178. https://doi.org/10.2307/2077795

[8] Pecorino, P. (1997) The Optimal Rate of Inflation When Capital Is Taxed. Journal of Macroeconomics, 19, 657-673. https://doi.org/10.1016/S0164-0704(97)00035-9

[9] Gokan, Y. (2002) Alternative Government Financing and Stochastic Endogenous Growth. Journal of Economic Dynamics and Control, 26, 681-706. https://doi.org/10.1016/S0165-1889(00)00080-4

[10] Levhari, D. and Patinkin, D. (1968) The Role of Money in a Simple Growth Model. American Economic Review, 58, 713-753.

[11] Fischer, S. (1974) Money and the Production Function. Economic Inquiry, 12, 517-533. https://doi.org/10.1111/j.1465-7295.1974.tb00419.x

[12] Benhabib, J., Schmitt-Grohé, S. and Uribe, M. (2001) Monetary Policy and Multiple Equilibria. American Economic Review, 91, 167-186. https://doi.org/10.1257/aer.91.1.167

[13] Meng, Q. and Yip, C.K. (2004) Investment, Interest Rate Rules, and Equilibrium Determinacy. Economic Theory, 23, 863-878. 
https://doi.org/10.1007/s00199-003-0401-4

[14] Suen, M. and Yip, C. (2005) Superneutrality, Indeterminacy and Endogenous Growth. Journal of Macroeconomics, 27, 579-595.

https://doi.org/10.1016/j.jmacro.2004.03.002

[15] Shaw, M., Lai, C. and Chang, W. (2005) Anticipated Policy and Endogenous Growth in a Small Open Monetary Economy. Journal of International Money and Finance, 24, 719-743. https://doi.org/10.1016/j.jimonfin.2005.04.003

[16] Lai, C.-C. and Chin, C.-T. (2013) Monetary Rules and Endogenous Growth in an Open Economy. Macroeconomic Dynamics, 17, 431-463. https://doi.org/10.1017/S1365100511000277

[17] Sinai, A. and Stokes, H. (1972) Real Money Balances: An Omitted Variable from the Production Function? Review of Economics and Statistics, 54, 290-296. https://doi.org/10.2307/1937990

[18] Simos, E.O. (1981) Real Money Balances as a Productive Input: Further Evidence. Journal of Monetary Economics, 7, 207-225. https://doi.org/10.1016/0304-3932(81)90043-X

[19] Hasan, M. and Mahmud, S. (1993) Is Money an Omitted Variable in the Production Function? Some Further Results. Empirical Economics, 18, 431-445. https://doi.org/10.1007/BF01176197

[20] Saygili, H. (2009) Transaction Costs, Productive Efficiency and Financial Account Management. Journal of Economic Studies, 36, 284-295. https://doi.org/10.1108/01443580910983861

[21] Chen, S., Shaw, M., Lai, C. and Chang, J. (2008) Interest-Rate Rules and Transitional Dynamics in an Endogenously Growing Open Economy. Journal of International Money and Finance, 27, 54-75. https://doi.org/10.1016/j.jimonfin.2007.09.009

[22] Ogaki, M. and Reinhart, C.M. (1998) Measuring Intertemporal Substitution: The Role of Durable Goods. Journal of Political Economy, 106, 1078-1098.

https://doi.org/10.1086/250040 


\section{Appendix}

\section{Appendix A. Transversality Condition}

From Equations (4) and (10), the household's budget constraint can be rewritten as follows:

$$
\dot{a}=r a-c .
$$

To satisfy the transversality condition, differentiating Equation (11) with respect to $t$ must be negative. Using Equations (7) and (A-1), we obtain:

$$
\frac{\dot{\lambda}}{\lambda}+\frac{\dot{a}}{a}-\rho=-\frac{c}{a} c
$$

From Equations (9) and (A-1), and the no-Ponzi game condition, we have:

$$
\frac{c}{a}=\frac{(\sigma-1) r+\rho}{\sigma} .
$$

Thus, when $\sigma \geq 1$, the transversality condition is always satisfied.

\section{Appendix B. Uniqueness and Stability Conditions}

First, we derive the existence condition of the equilibrium. From (19), the equilibrium value of $\omega$ must satisfy the following equation:

$$
\left(1-\tau_{y}\right)\left(f(\omega)-f^{\prime}(\omega) \omega\right) S(\omega)+(1-g) \frac{f(\omega)}{\omega}=\frac{\rho}{\sigma}
$$

where $S(\omega)=\frac{1}{\sigma}-1-\frac{1}{\omega}$. We call the left-hand side of Equation (B-1) $F(\omega)$.

Based on $S(0)=-\infty$ and $S(\infty)=\frac{1}{\sigma}-1$, the properties of $F(\omega)$ are:

$$
\begin{aligned}
& \lim _{\omega \rightarrow 0} F(\omega)=\lim _{\omega \rightarrow 0}\left(1-\tau_{y}\right)\left(f(\omega)-f^{\prime}(\omega) \omega\right) S(\omega)+\lim _{\omega \rightarrow 0} \frac{(1-g) f(\omega)}{\omega}=\infty, \\
& \lim _{\omega \rightarrow \infty} F(\omega)=\lim _{\omega \rightarrow 0}\left(1-\tau_{y}\right)\left(f(\omega)-f^{\prime}(\omega) \omega\right) S(\omega)+\lim _{\omega \rightarrow 0} \frac{(1-g) f(\omega)}{\omega}=-\infty .
\end{aligned}
$$

Thus, we can obtain the unique equilibrium value of $\omega$ from (B-1), if $F^{\prime}(\omega)$ is negative. Namely:

$$
F^{\prime}=-\left[\left(g-\tau_{y}\right) \frac{f^{\prime}(\omega) \omega-f(\omega)}{\omega^{2}}-\left(1-\tau_{y}\right) f^{\prime \prime}(\omega) \omega\left(1+\frac{1}{\omega}-\frac{1}{\sigma}\right)\right]<0 .
$$

Next, we examine the dynamic property of the equilibrium and derive the condition for the equilibrium to be determinate. Linearizing Equations (17) and (18) around a BGP, we obtain the following:

$$
\left(\begin{array}{c}
\dot{\chi} \\
\dot{\omega}
\end{array}\right)=\left(\begin{array}{cc}
\chi^{*} & \xi_{12} \\
\omega^{*} & \xi_{22}
\end{array}\right)\left(\begin{array}{c}
\chi-\chi^{*} \\
\omega-\omega^{*}
\end{array}\right) .
$$

where

$$
\chi^{*} \equiv-\frac{1}{\sigma}\left[\left(1-\tau_{y}\right)\left(f\left(\omega^{*}\right)-f^{\prime}\left(\omega^{*}\right) \omega^{*}\right)-\rho\right]+(1-g) f,
$$




$$
\begin{aligned}
\xi_{12} \equiv & \chi^{*}\left[-\frac{1}{\sigma}\left(1-\tau_{y}\right) f^{\prime \prime}\left(\omega^{*}\right) \omega^{*}-f^{\prime}\left(\omega^{*}\right)(1-g)\right], \\
\xi_{22} \equiv & \omega^{*}\left[\left(g-\tau_{y}\right)\left(\frac{f^{\prime}\left(\omega^{*}\right) \omega^{*}-f\left(\omega^{*}\right)}{\omega^{* 2}}\right)\right. \\
& \left.-\left(1-\tau_{y}\right)\left(1+\omega^{*}\right) f^{\prime \prime}\left(\omega^{*}\right)-f^{\prime}\left(\omega^{*}\right)(1-g)\right] .
\end{aligned}
$$

The trace, $T$, and determinant, $D$, of the coefficient matrix from Equation (B-3) are given by:

$$
\begin{aligned}
D= & \chi^{*} \xi_{22}-\omega^{*} \xi_{12} \\
= & \chi^{*} \omega^{*}\left[\left(g-\tau_{y}\right)\left(\frac{f^{\prime}\left(\omega^{*}\right) \omega^{*}-f\left(\omega^{*}\right)}{\omega^{* 2}}\right)-\left(1-\tau_{y}\right)\left(1+\omega^{*}\right) f^{\prime \prime}\left(\omega^{*}\right)\right. \\
& \left.-f^{\prime}\left(\omega^{*}\right)(1-g)\right]-\omega^{*} \chi^{*}\left[-\frac{1}{\sigma}\left(1-\tau_{y}\right) f^{\prime \prime}\left(\omega^{*}\right) \omega^{*}-f^{\prime}\left(\omega^{*}\right)(1-g)\right] \\
= & \chi^{*} \omega^{*}\left[\left(g-\tau_{y}\right)\left(\frac{f^{\prime}\left(\omega^{*}\right) \omega^{*}-f\left(\omega^{*}\right)}{\omega^{* 2}}\right)-\left(1-\tau_{y}\right) f^{\prime \prime}\left(\omega^{*}\right) \omega^{*}\left(1+\frac{1}{\omega}-\frac{1}{\sigma}\right)\right] . \\
T= & \chi^{*}+\omega^{*}\left[\left(g-\tau_{y}\right)\left(\frac{f^{\prime}\left(\omega^{*}\right) \omega^{*}-f\left(\omega^{*}\right)}{\omega^{* 2}}\right]\right. \\
& \left.-\left(1-\tau_{y}\right)\left(1+\omega^{*}\right) f^{\prime \prime}\left(\omega^{*}\right)-f^{\prime}\left(\omega^{*}\right)(1-g)\right] \\
= & -\frac{1}{\sigma}\left[\left(1-\tau_{y}\right)\left(f\left(\omega^{*}\right)-f^{\prime}\left(\omega^{*}\right) \omega^{*}\right)-\rho\right]+(1-g) f\left(\omega^{*}\right) \\
& +\left[\left(g-\tau_{y}\right)\left(\frac{f^{\prime}\left(\omega^{*}\right) \omega^{*}-f\left(\omega^{*}\right)}{\omega^{*}}\right)\right. \\
& +\frac{\rho}{\sigma}-\left(1-\tau_{y}\right)\left(1+\omega^{*}\right) f^{\prime \prime}\left(\omega^{*}\right) \omega^{*} \\
& \left.-\left(1-\tau_{y}\right)\left(1+\omega^{*}\right) f^{\prime \prime}\left(\omega^{*}\right) \omega^{*}-f^{\prime}\left(\omega^{*}\right)(1-g) \omega^{*}\right] \\
& \left(f\left(\omega^{*} \omega^{*}\right)-\frac{f^{\prime}\left(\omega^{*}\right) \omega^{*}-f\left(\omega^{*}\right)}{\omega^{*}}\left[-\frac{1}{\sigma}\left(1-\tau_{y}\right)+1+g\right]\right. \\
& {\left.\left[\omega^{*}\right) \omega^{*}\right)\left[-\frac{1}{\sigma}\left(1-\tau_{y}\right)-\frac{g-\tau_{y}}{\sigma}+1+g\right] \omega^{*} . }
\end{aligned}
$$

If (B-2) holds, $D>0$ and $T>0$. When $T>0$ and $D>0$, the coefficient 
matrix of (B-3) has two positive eigenvalues. Because both $\omega$ and $\chi$ are jumpable, we can state that if (B-2) holds, the economy jumps immediately to its $\mathrm{BGP}$ and is in a determinate equilibrium. 